\title{
Working Towards an Appropriate Use of Ibuprofen in Children: An Evidence-Based Appraisal
}

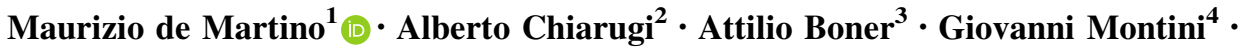 \\ Gianluigi L. de' Angelis ${ }^{5}$
}

Published online: 9 June 2017

(c) The Author(s) 2017. This article is an open access publication

\begin{abstract}
Ibuprofen is the most widely used non-steroidal anti-inflammatory drug (NSAID) for the treatment of inflammation, mild-to-moderate pain and fever in children, and is the only NSAID approved for use in children aged $\geq 3$ months. Its efficacy and safety profile have led to its increasing use in paediatric care, even without medical prescription. However, an increase of suspected adverse reactions to ibuprofen has been noted in concomitance with the raised, often medically unsupervised, consumption of the drug. The purpose of this work was a critical review of the paediatric literature over the last 15 years on side effects and adverse events associated with ibuprofen, in order to highlight circumstances associated with higher risks and to promote safe and appropriate use of this drug. The literature from 2000 to date demonstrates that gastrointestinal events are rare, but (when they occur) include both upper and lower digestive tract lesions. Dehydration
\end{abstract}

Maurizio de Martino

maurizio.demartino@unifi.it

1 Department of Health Sciences, Anna Meyer Children's University Hospital Florence, University of Florence, viale Pieraccini 24, 50139 Florence, Italy

2 Department of Health Sciences, Section of Clinical Pharmacology and Oncology, University of Florence, Florence, Italy

3 Pediatric Clinic, Department of Life and Reproduction Sciences, University of Verona, Verona, Italy

4 Pediatric Nephrology and Dialysis Unit, Department of Clinical Sciences and Community Health, University of Milan, Fondazione IRCCS Ca' Granda-Ospedale Maggiore Policlinico, Milan, Italy

5 Department of Women's and Children's Health, Gastroenterology and Pediatric Gastroenterology Unit, University of Parma, Parma, Italy plays an important role in triggering renal damage, so ibuprofen should not be given to patients with diarrhoea and vomiting, with or without fever. Likewise, ibuprofen should never be administered to patients who are sensitive to it or to other NSAIDs. It is contraindicated in neonates and in children with wheezing and persistent asthma and/or during varicella. Most of the analysed studies reported adverse events when ibuprofen was being used for fever symptoms or flu-like syndrome. Ibuprofen should not be used as an antipyretic, except in rare cases. Ibuprofen remains the drug of first choice in the treatment of inflammatory pain in children.

\section{Introduction}

Ibuprofen is the most widely used non-steroidal anti-inflammatory drug (NSAID) for the treatment of inflammation, mild-to-moderate pain and fever in children and, thanks to its good tolerability profile, the only NSAID approved for use in children over 3 months old.

Since its marketing as an oral suspension for paediatric use, ibuprofen has replaced acetylsalicylic acid for the treatment of inflammation, avoiding the risk of Reye's syndrome. In recent years, various reviews and metaanalyses have confirmed the good efficacy and tolerability profile of ibuprofen [1-3], especially when compared to other NSAIDs [4, 5]. However, precisely because of its good efficacy and safety, ibuprofen is being increasingly used in paediatric care, even without medical prescription.

In 2010, the Paediatric Working Group of the Italian Drugs Agency (AIFA) [6] noted an increase of suspected adverse reactions to ibuprofen and ketoprofen in concomitance with the increased consumption of the respective products (from 0.7 per 100,000 paediatric packs sold in 
2005 to 1.7 per 100,000 packs sold in the first 9 months of 2010).

The reported adverse reactions included gastrointestinal tract events, mostly bleeding, and some cases of renal damage. Cases were particularly related to the use of the NSAID in alternation or association with paracetamol, and in the presence of dehydration due to fever and/or other concomitant conditions such as vomiting and diarrhoea, often recurring during the influenza season.

According to Italian post-marketing data, the proportion of packs of ibuprofen for paediatric use bought without a medical prescription increased from $28 \%$ in 2008 to $70 \%$ in 2015. This medically unsupervised use of ibuprofen raises issues concerning the correct use of the drug by parents/caregivers and the risks of its misuse.

In parallel with the growing over-the-counter consumption of ibuprofen, there has recently been an increase in the number of publications on adverse events occurring in children taking ibuprofen and other NSAIDs, particularly as antipyretics. Emerging research has shown that the main side effects of ibuprofen involve the gastrointestinal system [7] and the kidneys [8], especially in feverish dehydrated individuals.

As far as infections of the respiratory tract are concerned, some studies indicate that ibuprofen increases the risk of suppurative complications of pneumonia in children [9].

In the light of emerging evidence on adverse reactions, the purpose of this paper was to critically review the literature on side effects and adverse events associated with ibuprofen when used as an antipyretic and analgesic in children, in order to highlight circumstances associated with higher risks, and to promote safe and appropriate use of the drug.

\subsection{Pharmacodynamic Properties}

Like all NSAIDs, ibuprofen inhibits the activity of cyclooxygenase (COX) which, by oxidizing arachidonic acid released from cell membrane phospholipids, produces prostaglandins, autacoids that play a key role in the pathogenesis of inflammation, fever and nociception. At present, we know that there are two isoforms of COX (COX-1 and COX-2), which have different active sites for arachidonic acid and, therefore, different sensitivities to inhibition by each NSAID.

Ibuprofen is pharmacodynamically active against both COX-1 and COX-2, although it shows slightly greater selectivity for COX-1. From a molecular point of view, the inhibitory action of ibuprofen toward both COX isoforms is competitive and reversible. This is of relevance not only to the therapeutic properties of ibuprofen, but also to its side effects. Indeed, reversibility of inhibition allows full recovery of enzymatic activity upon metabolism and elimination of ibuprofen. This leads to prompt return of constitutive synthesis of prostaglandins, restoring their functions in organs such as the stomach and kidneys, thus reducing the potential side effects of ibuprofen. Interestingly, alongside COX inhibition, an additional mechanism by which ibuprofen provides analgesia is improved synthesis of endocannabinoids [10].

\subsection{Pharmacokinetic Properties}

Ibuprofen exists in pharmaceutical and galenic formulations as a diastereo-isomeric mixture of the $\mathrm{S}(+)$ enantiomer, which is pharmacologically active as a COX inhibitor, and the $\mathrm{R}(-)$ enantiomer, which is a weaker COX inhibitor but is endowed with additional anti-inflammatory properties [10].

Importantly, conversion of the dextro- into the levoisomer occurs through the process called "chiral inversion", which in general mainly occurs in the liver, even though for ibuprofen an inversion in the gastrointestinal tract has also been proposed. As for the clinical implication of this isomer inversion, in principle it might be responsible for substantial therapeutic effects in different patient populations. In practice, however, with the exception of severe hepatic disorders such as liver cirrhosis in which an increase of the $\mathrm{R} / \mathrm{S}$ isomer plasmatic ratio has been reported, alterations of ibuprofen chiral inversion do not appear to cause significant pharmacotherapeutic problems. The same is true for children, where pharmacokinetic parameters of ibuprofen in children are the same as those in adults (Table 1). Differences, however, are a higher blood concentration of the $\mathrm{S}(+)$ than the $\mathrm{R}(+)$ enantiomer, and a greater half-life variation in children [10].

Again, from a clinical point of view, however, these differences do not appear to cause substantial therapeutic effects. Indeed, even the apparent higher antipyretic potency of ibuprofen in children younger than 6 years, does not seem related to differences in pharmacokinetic parameters but to an increased skin area/bodyweight ratio

Table 1 Pharmacokinetics of ibuprofen in children [10]

\begin{tabular}{ll}
\hline Oral absorption & $T_{1 / 2}: 0.3-0.9 \mathrm{~h}$ \\
& $T_{\max }: 1-2 \mathrm{~h}$ \\
& $10 \mathrm{mg} \mathrm{kg}^{-1} \rightarrow C_{\max }: 44 \mathrm{mg} \mathrm{L}^{-1}$ \\
Protein binding & $99 \%$ \\
Active isomer & $\mathrm{S}(+)$ \\
Plasma concentration & $\mathrm{S}(+)$ children $<$ adults \\
Metabolism & $\mathrm{CYP} 4502 \mathrm{C} 9$ and $2 \mathrm{C} 8$ \\
$T_{1 / 2}$ & $0.9-2.3 \mathrm{~h}$ \\
\hline
\end{tabular}

$T_{1 / 2}$ half-life, $T_{\max }$ time to $\mathrm{C}_{\max }, C_{\max }$ maximum concentration, CYP450 cytochrome $\mathrm{P} 450$ 
that favours loss of body temperature. Allelic variants of CYP2C8 play a key role in the pharmacokinetics and metabolism of ibuprofen and could explain some of the side effects in children [11]. Lastly, it is worth noting that a detailed and reliable plasma concentration/therapeutic effect relationship for ibuprofen is currently lacking. Such a relationship might certainly help to understand how a specific therapeutic regimen and the related plasma concentrations translate into therapeutic effects of clinical relevance.

\subsection{Clinical Evidence of Efficacy for Ages as Young as 3 Months}

Ibuprofen is widely used for the treatment of inflammation, acute and chronic pain and in the management of fever. Although other NSAIDs, such as ketoprofen, are also indicated in children, ibuprofen is the only one that can be used in 3-month old infants because of its efficacy and safety profile.

In children, ibuprofen was shown to be effective in shortening duration of and improving relief from fever [12], as well as in reducing musculoskeletal pain [13], headache [14] and dental pain [15]. Ibuprofen is also appropriate for the relief of inflammatory pain in patients with acute otitis media, pharyngitis and tonsillitis. In a multicentre randomised controlled trial in 219 children, Bertin et al. demonstrated the efficacy of ibuprofen in acute painful inflammation of the middle ear [16]. The same group confirmed that ibuprofen is also effective in the relief of painful swallowing in children with tonsillitis or pharyngitis [17].

In a systematic review of 18 studies on analgesic efficacy in children, no statistically significant differences were found between paracetamol and ibuprofen in 11 studies; in 6 studies, ibuprofen was superior to paracetamol, whereas in 1 study paracetamol was found to be more effective than ibuprofen. The review also considered 30 studies on antipyretic efficacy in children; 15 of the studies reached the conclusion that ibuprofen treatment was better than acetaminophen treatment, while the remaining 15 studies found no significant differences between the two treatments. However, it should be considered that only 7 of the 30 studies were randomized controlled trials with enough information to calculate a standardized mean difference [2].

Recently, ibuprofen has also been associated or alternated with paracetamol to boost the analgesic/antipyretic effects of the latter. Although associations can obviously show additive or even synergistic effects, currently the combination of paracetamol and ibuprofen, whether given alternately or together, is not recommended for the treatment of fever [18]. There is insufficient evidence to state that combined/alternating treatment in febrile states can be of more benefit, considering that the clinical efficacy of $15 \mathrm{mg} / \mathrm{kg}$ paracetamol monotherapy currently enables excellent management of the symptom.

Given its anti-inflammatory activity, ibuprofen is the treatment of choice for pain with an inflammatory component, such as that in arthritis. Kermond et al. tested the efficacy of ibuprofen in transient synovitis of the hip in 36 children aged 1-12 years, who were treated with ibuprofen ( $n=17)$ or placebo $(n=19)$ [19]. Although transient synovitis is a self-limiting condition with spontaneous resolution within a week, the investigators found that the treatment with ibuprofen reduced the duration of symptoms, without causing serious adverse events. Indeed, although the disorder resolved within 7 days in $80 \%$ of the patients of both groups, the mean duration of symptoms was shorter in the group treated with ibuprofen (2 days) than in that receiving placebo (4.5 days) [19].

The efficacy of ibuprofen was also investigated in a multicentre, open-label study in 46 children aged between 18 months and 13 years affected by chronic juvenile arthritis. Disease severity, active joint count and any side effects were assessed at each clinical visit, usually monthly. The results of this study showed that after 2 months of treatment there was a statistically significant reduction in the swollen and/or tender joints. Moreover, as judged by physicians on a visual analogue scale, there were statistically significant reductions of disease severity after 1, 2 and 3 months of therapy, compared to the pre-treatment situation. The adverse events were mainly gastrointestinal. Overall, the study showed that ibuprofen was a well-tolerated anti-inflammatory agent for the treatment of juvenile arthritis [20].

As far as the use of ibuprofen for pain treatment is concerned, a randomised controlled study was conducted to compare oral morphine $0.5 \mathrm{mg} / \mathrm{kg}$ and oral ibuprofen $10 \mathrm{mg} / \mathrm{kg}$ in children with uncomplicated limb fractures. Results showed that efficacy of the two analgesics was the same, although patients receiving morphine had more side effects (56.1 vs. $30.9 \%, p<0.01$ ) [21]. In keeping with evidence of comparable efficacy, the use of ibuprofen is an effective strategy for reducing the consumption of opioids for post-operative pain, thus leading to fewer opioid-related adverse events [22].

The anti-inflammatory properties of ibuprofen also underlie the rationale for its use in patients with cystic fibrosis, and this drug should be preferred to corticosteroids because of its fewer adverse events [23, 24]. Specifically, ibuprofen was evaluated in a randomised, placebo-controlled, double-blind study in 85 patients with cystic fibrosis aged between 5 and 39 years. Compared to those receiving placebo, patients given ibuprofen had a smaller annual decrease in forced expiratory volume, and reduction 
of inflammation as evidenced by chest X-ray analysis [24]. The conclusions drawn from another recent study in 52 children with cystic fibrosis were that the reduction in inflammation achieved by ibuprofen can slow the loss of lung function, while having little effect on renal parameters [25].

Overall, ibuprofen is confirmed as the drug of first choice in the treatment of inflammatory pain in children.

Search strategies and sources on safety and tolerability of ibuprofen

Literature search: PubMed

Keywords: ibuprofen kidney, ibuprofen acute kidney injury, ibuprofen acute interstitial nephritis; ibuprofen gastrointestinal, ibuprofen gastro, ibuprofen gut, ibuprofen intestinal, ibuprofen upper gastrointestinal bleeding, ibuprofen lower gastrointestinal bleeding; ibuprofen liver, ibuprofen hepatic; ibuprofen lung, ibuprofen suppurative pneumonic complications, ibuprofen suppurative pneumonia complications, ibuprofen parapneumonic empyema; ibuprofen and asthma and children, ibuprofen and asthma, ibuprofen and varicella, ibuprofen and Stevens-Johnson syndrome

Article types: clinical trials, reviews, case reports

Publication date: 15 years (2000-2015)

Species: humans

Ages: child (birth to 18 years); infants treated with ibuprofen to promote the closure of patent ductus arteriosus were excluded

Patent ductus arteriosus. Exploiting its anti-cyclooxygenase inhibitory activity, ibuprofen is effective in closing patent ductus arteriosus in preterm, low birth weight, or preterm and low birth weight infants. Ibuprofen ( $5 \mathrm{mg} / \mathrm{mL}$ solution for injection) is currently considered the drug of choice, as compared to indomethacin, because ibuprofen is as effective as indomethacin, but presents fewer side effects. As a matter of fact, ibuprofen reduces the risk of transient renal insufficiency and of necrotising enterocolitis. Oro-gastric administration of ibuprofen appears as effective as intravenous administration [26].

\section{Safety and Tolerability of Ibuprofen}

Overall, 55 relevant publications were identified, including reviews, randomised clinical trials, observational clinical studies and case reports. In detail, 12 focused on gastrointestinal tolerability, 11 on renal tolerability, 7 on pulmonary tolerability, 12 on ibuprofen and asthma, 5 on the use of the drug in patients with varicella, 4 on StevensJohnson syndrome, and 4 on hepatic tolerability. Single studies are presented below, grouped according to system, organ or condition.

\subsection{Gastrointestinal Tolerability}

Epidemiological studies and controlled clinical trials have demonstrated that ibuprofen is among the NSAIDs associated with the lowest risk of severe gastrointestinal adverse events [10].

NSAIDs can cause damage to both the epithelium and the micro-vessels of the digestive tract. There are two main mechanisms of gastrointestinal damage due to NSAIDs: a local effect related to an alteration of the mucosal barrier and a systemic effect due to the inhibition of COX with a consequent reduction in the synthesis of prostaglandins.

Prostaglandins play an important role in protecting the gastric mucosa from acid-related damage by inhibiting the production of hydrochloric acid by the gastric parietal cells and increasing the production of a protective mucus by the epithelial cells lining the stomach. High doses or repeated, prolonged treatment with an NSAID can, on the one hand, remove the inhibition of activation of parietal cells by gastrin, histamine and acetylcholine and, on the other hand, decrease the barrier effect of the mucus that protects the gastric mucosa [27]. In more detail, NSAID-induced gastric lesions are caused by a gradual deterioration of the superficial layer of muco-phospholipids, which is followed by damage to the mucosal cells, local microcirculation and acid-secreting parietal cells. Damage to endothelial cells of blood vessels is thought to be the consequence of the release of free radicals, protein oxidation, and inhibited production of nitric oxide and prostaglandins. These phenomena translate clinically into gastrointestinal tract bleeding, peptic ulcer and erosive gastritis. In addition, in the small intestine several mechanisms take place: the enterohepatic cycle of the NSAIDs conjugated with bile acids, and their deconjugation by intestinal bacteria with the release of active molecules and consequent stimulation of local immunological reactions [28]. The lack of acid, but presence of both bacteria and bile in this part of the gastrointestinal tract, favour the development of ulcers.

From a clinical point of view, the administration of NSAIDs can hesitate in the onset of a broad spectrum of symptoms and in organic lesions.

Although the aim of this paper is not specifically focused on symptoms caused by NSAIDs, it is well known that vague and nonspecific manifestations are often referred to by patients of any age, including dyspepsia, heartburn and nausea [29].

Overall, the side effects of NSAIDs can be divided into minor and serious [29].

Complications of the upper gastrointestinal tract are well-recognised problems, whereas the less common but potentially more severe complications of the lower gastrointestinal tract are often overlooked, by patients and physician, even though the more widespread use of 
technologies, such as video capsule endoscopy and balloon endoscopy, has increased the feasibility of documenting mucosal damage throughout the entire digestive tract [30].

The spectrum of possible NSAID-induced lesions is broad and includes increased intestinal permeability, anaemia, inflammation, diarrhoea, perforation, diverticulitis, ulcers and stenosis of the gastrointestinal tract [31].

Furthermore, there is clear evidence that prostaglandin production is increased in patients with active inflammatory bowel disease. Prostaglandin levels correlate with disease activity and decrease with successful medical intervention. Disease activity has also been correlated with COX expression, especially COX-2. In fact, prostaglandins seem to play a protective role and be involved in tissue repair processes. Consequently, NSAIDs are contraindicated in chronic inflammatory bowel disease, being potential co-causes of exacerbations of the disease [32].

Although there are fewer studies on the effects of NSAIDs on the gastrointestinal tract in children than in adults, there is substantial body of evidence on this issue in the paediatric population.

Bianciotto et al. [33] evaluated the risks of upper gastrointestinal complications associated with the use of various drugs (NSAIDs, oral steroids and antibiotics) in paediatric age. Their study included children admitted to the emergency room of eight clinical centres for upper gastrointestinal complications (with endoscopically confirmed gastroduodenal lesions or clinically diagnosed haematemesis or melena); children admitted for neurological disorders formed the control group. In the period 1999-2010, 486 children with upper gastrointestinal complications and 1930 children with neurological disorders were enrolled. Recent use of drugs (for brief periods: 1-8 days) was greater in the group with upper gastrointestinal complications than in the controls (73 vs. 54\%; $p<0.001)$. The complications were related to the use of NSAIDs, oral steroids and antibiotics. The mean duration of the use of ibuprofen in this study was 4 days, showing that upper gastrointestinal complications can occur even during short courses of treatment [33].

Grimaldi-Bensouda et al. [34] studied 177 children (aged between 2 months and 16 years) with upper gastrointestinal tract bleeding. Among these 177 children, 83 were prescribed at least one NSAID in the 7 days preceding the admission (58/73 ibuprofen). The authors confirmed that bleeding of the upper gastrointestinal tract is a rare event; nevertheless, in one-third of the cases, it could be attributed to exposure to NSAIDs administered at analgesic or antipyretic doses [34].

The risk of ibuprofen-induced gastrointestinal bleeding is higher in patients who take more than one type of
NSAID simultaneously (because of a synergistic effect) and/or platelet antiaggregants/anticoagulants [35]. Other predisposing factors are a positive history of peptic ulcer or gastrointestinal bleeding, Helicobacter pylori infection, diverticulosis or chronic inflammatory bowel disease. With regard to these conditions at risk, Usta et al. [36] evaluated the respective roles of NSAIDs and $H$. pylori infection in the aetiology of upper gastrointestinal bleeding in 188 children (82 females and 106 males; mean age $8.43 \pm 5.24$ years) admitted to a paediatric gastroenterology unit. Endoscopic examination revealed oesophageal, gastric and duodenal mucosa damage in 37 , 58 and $24.5 \%$ of the patients, respectively. The exact site of the bleeding remained unknown in $14.4 \%$ of the cases. In $21.3 \%$ of the cases, the patients had taken drugs prior to their admission to the hospital; in particular, $47.5 \%$ had taken ibuprofen, 35\% acetylsalicylic acid and $17.5 \%$ other NSAIDs. H. pylori infection was found in $20.7 \%$ of the children. The authors concluded that there is a positive correlation between ibuprofen or acetylsalicylic acid intake and upper gastrointestinal bleeding, whereas there was no significant connection with $H$. pylori, although this bacterium is a well-known cause of gastritis [36]. Table 2 summarises the literature regarding ibuprofen-induced gastrointestinal adverse events over the last 15 years.

Although ibuprofen is one of the NSAIDs associated with a lower risk of serious gastrointestinal adverse events, its therapeutic use in children and adults must be accompanied by awareness of its possible adverse effects, which can present throughout the entire gastrointestinal tract. The most frequent gastrointestinal adverse event is bleeding, which can be minimised or avoided by limiting the use of ibuprofen to strict therapeutic indications and co-administering appropriate gastroprotection.

In particular, it is indicated to administer ranitidine or a proton pump inhibitor (PPI), with a superiority of the PPI, accordingly with several recent studies [37]. Considering the paediatric age, it is recommended the use of histamine-2 receptor antagonists (H2RAs) or selected PPIs, accordingly to the European Society for Paediatric Gastroenterology Hepatology and Nutrition/North American Society for Pediatric Gastroenterology, Hepatology and Nutrition (ESPGHAN NASPGHAN) guidelines [38, 39].

It is also essential to consider the patient's past history, evaluating possible contraindications to the use of NSAIDs, such as chronic inflammatory bowel disease or treatment with antiplatelet agents/anticoagulants. Although data from children are limited, it has been demonstrated that NSAIDs can cause gastrointestinal damage even when taken for a short period; signs and symptoms of possible 


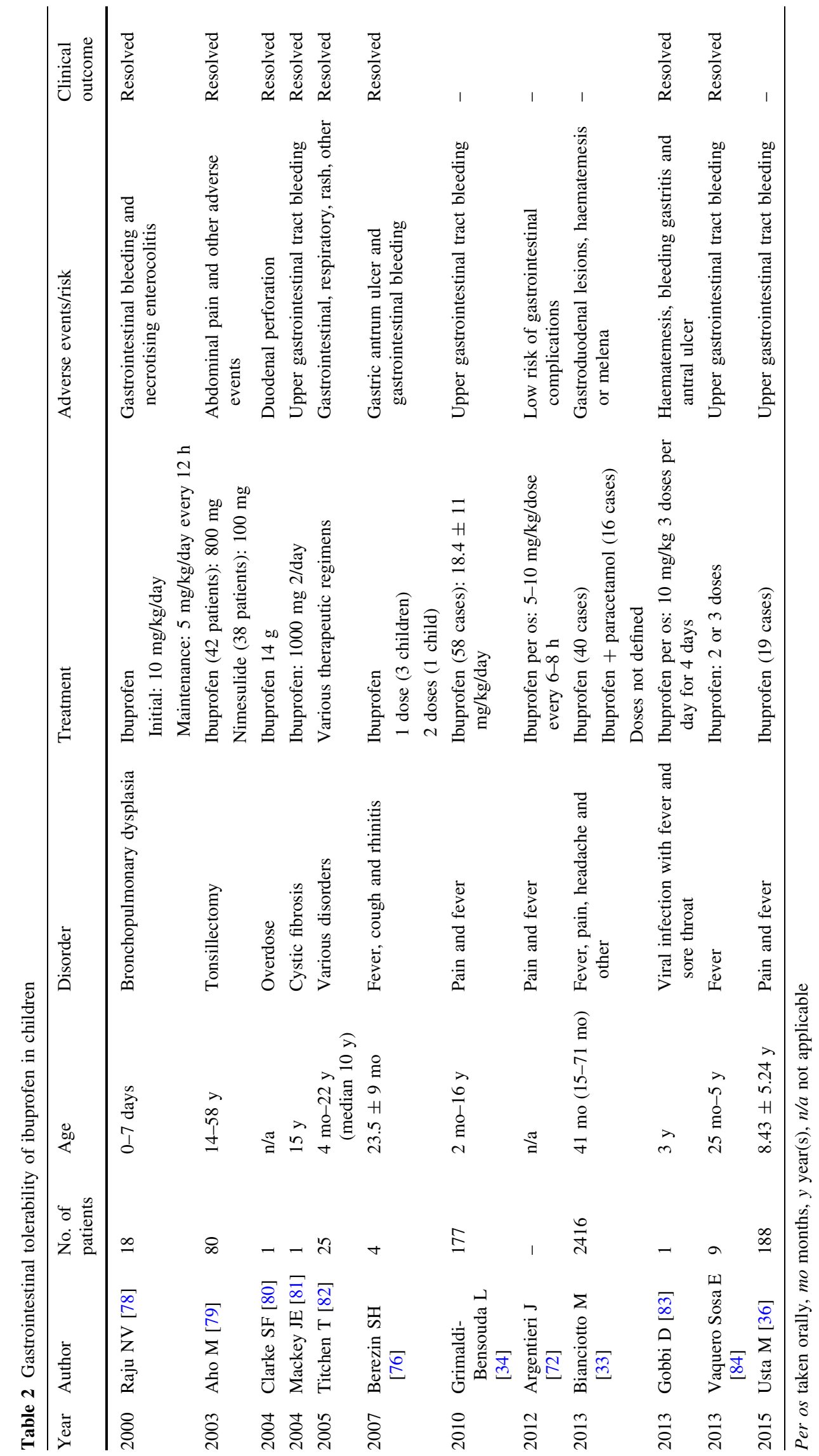


effects on the small bowel and colon should not be overlooked.

Key points: gastrointestinal tolerability

All parts of the gastrointestinal tract can, potentially, be affected

Damage to the upper gastrointestinal tract is usually mild and reversible

Damage may occur even with short courses of treatment

It is important to consider possible contraindications to the use of NSAIDs, such as chronic inflammatory bowel disease

Ibuprofen should not be taken on an empty stomach

\subsection{Renal Tolerability}

Over the years, nephrologists and paediatricians have expressed concern regarding the risks of serious renal adverse effects related to the use of NSAIDs in children [10], because of the capacity of these drugs to reduce the renal synthesis of prostaglandins. In euvolaemic states, prostaglandins have a negligible effect on renal haemodynamics, but in cases of hypovolaemia, up-regulation of the renin-angiotensin system, as well as of the catecholaminergic system, causes systemic and renal vasoconstriction, which leads to production of renal prostaglandins with the aim of maintaining renal perfusion and glomerular filtration. This protective effect is inhibited by ibuprofen.

Febrile children are at an increased risk of dehydration because of greater insensible fluid loss (for example, sweating) and the commonly present difficulty in consuming liquids. The milder forms of dehydration can be difficult to detect in children and may go unnoticed. The patient's clinical conditions can evolve with worsening dehydration because of the onset of diarrhoea and vomiting. Various authors have recommended not using ibuprofen in the treatment of pronounced fever or for mildto-moderate pain in infants and children who are dehydrated or could become so during the course of the disease, because of an increased risk of acute renal failure [40-42].

In detail, Ulinski et al. reported on 6 patients (including 1 kidney transplant recipient), aged between 4 and 15 years, who developed acute renal failure following therapeutic doses of ibuprofen. Renal impairment developed 1-3 days after treatment with ibuprofen, but the levels of creatinine returned to normal within 3-9 days following rehydration and withdrawal of the NSAID [40]. Wong et al. also advised against the use of ibuprofen in preschool infants with fever/pain and dehydration [41]. Leroy et al. reported an increased risk of acute renal failure in patients with hypovolaemia following treatment with ibuprofen [42]. Balestracci et al. studied 105 children with acute gastroenteritis, 46 of whom developed acute kidney injury: $54 \%(34 / 63)$ of the patients treated with ibuprofen and $26 \%(12 / 46)$ of those not treated with the NSAID, demonstrating that ibuprofen treatment is a risk factor for the development of acute renal injury independently of the degree of hydration (OR 2.47 [95\% CI 1.78-3.42]). The children who developed acute renal injury tended to be younger (0.66 vs. 1.74 years; $p<0.001)$ and had more frequently taken ibuprofen ( 74 vs. $49 \%, p=0.01$ ). The authors emphasised that children under 6 months old have a higher risk of ibuprofen-related renal toxicity [8].

Misurac et al. studied the relationship between acute renal injury and NSAID intake in children [43]. They retrospectively analysed the clinical records of 1015 children with a diagnosis of acute kidney injury: in 27 (2.7\%) (aged between 0.5 and 17.7 years) an association with NSAIDs was found, and in 18 of these cases the drug involved was ibuprofen. Of the 27 patients with acute kidney injury, 21 had clinical, laboratory, radiographic and/or pathological signs of acute tubular necrosis, while 6 had evidence of acute interstitial nephritis. Ibuprofen was taken alone $(67 \%)$ or together with naproxen $(7 \%)$ or ketorolac $(7 \%)$. Children $<5$ years of age were more likely to require dialysis $(p<0.001)$, be admitted to an intensive care unit $(p=0.013)$ and stay longer in hospital $(p=0.037)$. The authors concluded that NSAIDs, administered at normal doses, accounted for $2.7 \%$ of the cases of acute renal injury and that damage to the kidneys may be more severe in younger children [43].

Another side effect of ibuprofen that has been described is interstitial nephritis. Gallego et al. [44] and Dixit et al. [45] reported two cases of acute renal failure due to acute tubulo-interstitial nephritis that developed after administration of aspirin and ibuprofen in succession. Krause described the cases of seven children, aged between 13 and 17.5 years, who developed acute renal failure following treatment with NSAIDs, including ibuprofen; six of the seven patients had taken more than one type of NSAID and none reported previous kidney disease or concomitant treatment with other drugs [46].

Table 3 summarises the literature regarding ibuprofenassociated renal adverse events in children over the last 15 years.

In conclusion, ibuprofen-induced acute kidney injury is a rare but severe occurrence in children and is (fortunately) usually reversible following suspension of treatment with the NSAID. Care must be taken when giving ibuprofen to children at risk of dehydration (i.e. those with fever, vomiting and/or diarrhoea), children with pre-existing renal disorders and to those taking potentially nephrotoxic drugs. Under these circumstances, NSAIDs should only be used if there are no alternatives and at the minimum effective dose. Careful use of NSAIDs is particularly important in children who were born prematurely or with a low birthweight, 
Table 3 Renal tolerability of ibuprofen in children

\begin{tabular}{|c|c|c|c|c|c|c|}
\hline Year & Author & $\begin{array}{l}\text { No. of } \\
\text { patients }\end{array}$ & Disorder & Treatment & Adverse events/risk & $\begin{array}{l}\text { Clinical } \\
\text { outcome }\end{array}$ \\
\hline 2000 & $\begin{array}{l}\text { Gallego N } \\
\text { [44] }\end{array}$ & 1 & Flu-like syndrome & Ibuprofen and aspirin & Tubulo-Interstitial-nephritis & Resolved \\
\hline 2001 & $\begin{array}{l}\text { Del Vecchio } \\
\text { MT [85] }\end{array}$ & 1 & Febrile seizures & Ibuprofen and paracetamol & Acute renal failure & Resolved \\
\hline 2001 & $\begin{array}{l}\text { Wong W } \\
\text { [41] }\end{array}$ & 1 & $\begin{array}{l}\text { Diarrhoea, vomiting and } \\
\text { fever }\end{array}$ & $\begin{array}{l}\text { Paracetamol as initial } \\
\text { treatment } \\
\text { Ibuprofen } 5 \mathrm{mg} / \mathrm{kg} / \text { dose 3/day }\end{array}$ & Acute renal failure & Resolved \\
\hline 2004 & $\begin{array}{l}\text { Moghal NE } \\
{[86]}\end{array}$ & 1 & Flu-like syndrome & Ibuprofen (50 mg, 6 doses) & Mild cortical necrosis & Resolved \\
\hline 2004 & $\begin{array}{l}\text { Ulinski T } \\
\text { [40] }\end{array}$ & 7 & $\begin{array}{l}\text { Fever, diarrhoea and } \\
\text { vomiting }\end{array}$ & $\begin{array}{l}\text { Ibuprofen }(n=6) \text { : } \\
11.5-32 \mathrm{mg} / \mathrm{kg} / \text { day } \\
\text { Ketoprofen }(n=1): 7.5 \\
\mathrm{mg} / \mathrm{kg}\end{array}$ & Acute renal failure & Resolved \\
\hline 2005 & Krause I [46] & 7 & $\begin{array}{l}\text { Suicide attempt, fractures, } \\
\text { headache }\end{array}$ & Ibuprofen ( 3 cases): $0.8-1.6 \mathrm{~g}$ & Acute renal failure & Resolved \\
\hline 2007 & Leroy S [42] & - & Pain and fever & Ibuprofen: various doses & Acute renal failure & - \\
\hline 2008 & $\begin{array}{l}\text { Dixit MP } \\
\text { [45] }\end{array}$ & 1 & Fever & Ibuprofen and aspirin & Acute renal failure & Resolved \\
\hline 2013 & $\begin{array}{l}\text { Misurac JM } \\
{[43]}\end{array}$ & 1015 & - & $\begin{array}{l}\text { Ibuprofen: } 18 \text { cases } \\
\text { Ibuprofen }+ \text { naproxen: } 2 \\
\text { cases } \\
\text { Ibuprofen + Ketorolac: } 2 \\
\text { cases }\end{array}$ & Acute kidney injury & - \\
\hline 2014 & Yue Z [87] & 47,803 & - & Ibuprofen + paracetamol & $\begin{array}{l}\text { Increased risk of acute } \\
\text { renal failure }\end{array}$ & - \\
\hline 2015 & $\begin{array}{l}\text { Balestracci } \\
\quad \text { A [8] }\end{array}$ & 105 & Acute gastroenteritis & Ibuprofen & Acute kidney injury & - \\
\hline
\end{tabular}

because these children have a reduced number of nephrons and are therefore at higher risk of renal impairment throughout their life. Chronic use of NSAIDs in such individuals is a strong risk factor, increasing the already high numbers developing chronic kidney disease [47].

Key points: renal tolerability

Ibuprofen inhibits the protective effects on prostaglandins on renal perfusion and glomerular filtration in cases of dehydration

The reduction in glomerular filtration is usually asymptomatic and reversible once ibuprofen has been suspended; the renal impairment rarely requires medical intervention or admission to hospital

The use of ibuprofen is contraindicated in children at risk of dehydration (i.e. those with fever, vomiting and/or diarrhoea)

Care must be taken with ibuprofen when treating children born prematurely or with a low birthweight because of their reduced nephron mass and therefore at higher risk of kidney damage

\subsection{Pulmonary Tolerability}

Various studies have shown that treatment with ibuprofen may be responsible for the worsening of some respiratory bacterial infections and the development of severe lung infections and complications, possibly as a result of reduced pulmonary blood flow and decreased production of inflammatory cytokines [48, 49].

In order to investigate a possible causality between the intake of NSAIDs and the development of severe bacterial infections in childhood, Leroy et al. prospectively analysed 5182 children admitted to hospital: of these, 32 had severe bacterial infections following treatment with NSAIDs in the 15 days prior to the admission. Bacteriological studies identified the presence of Staphylococcus aureus, group A streptococci (GAS) and Streptococcus pneumoniae. Ibuprofen, prescribed mainly for the treatment of fever, was the most frequently used NSAID (94\%) [50].

François et al. studied 767 children admitted to hospital because of pneumonia: 90/767 had complications such as empyema and/or lung abscesses. Multivariate analysis of the data revealed that ibuprofen was the only pre-admission treatment independently correlated with suppurative complications. The authors did, however, recommend caution in interpreting this information because it was not certain whether administration of the NSAID had preceded the development of the complication in all cases [9]. Elemraid et al. also investigated 


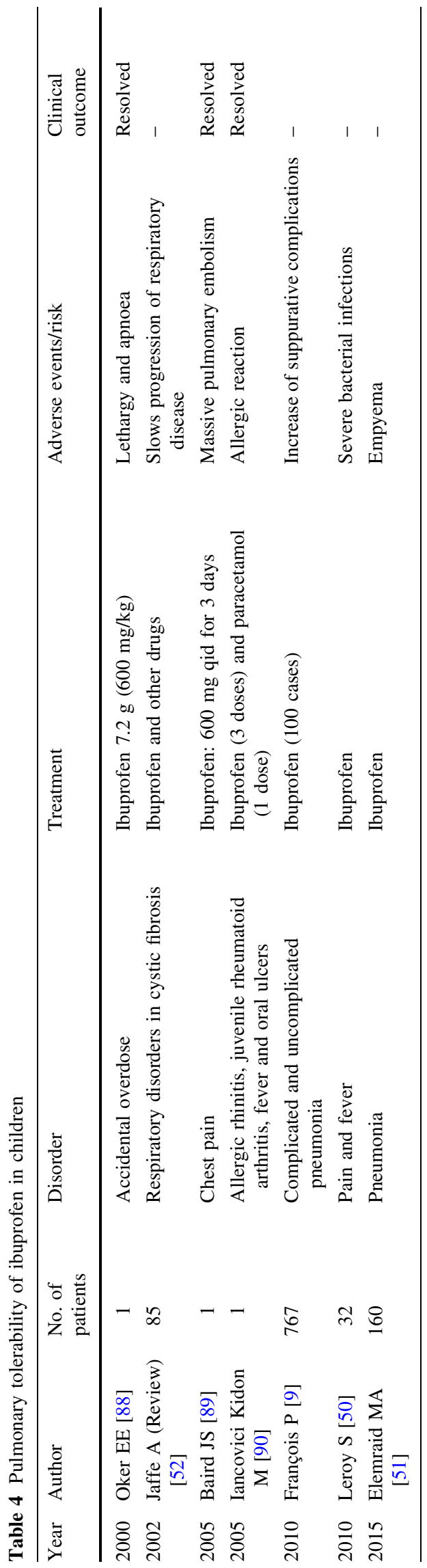

possible risk factors for the development of pleural complications in 160 children with community-acquired pneumonia and concluded that pre-admission administration of ibuprofen was associated with a higher risk of developing pleural empyema [51].

Table 4 summarises the data on adverse pulmonary events in children taking ibuprofen.

The published data on the use of ibuprofen in children with cystic fibrosis [52] are more reassuring in that it seems that the NSAID slows disease progression notably, without causing serious adverse events.

\subsubsection{Asthma}

Hypersensitivity cross-reactions to ibuprofen in children sensitive to aspirin have been reported [10]. The intake of ibuprofen can trigger bronchospasm and exacerbate the asthmatic symptoms of children with aspirin-induced asthma [53].

Valkhoff et al. [54] analysed various European databases (Germany, UK, The Netherlands and Italy) containing information on the demographics, diagnosis and pharmacological prescriptions of 7.7 million children and adolescents, of whom $17.3 \%$ had taken one of 45 NSAIDs for at least 1 day. The aim of the study was to evaluate the use of NSAIDs and related adverse events in the paediatric population. The authors found misuse of prescriptions for NSAIDs in all four countries; however, only for ibuprofen (the most widely prescribed NSAID) was it possible to identify an association $(R R=2)$ between consumption of the drug and exacerbation of asthma [54]. Sordillo et al. [55] investigated the potential correlation between antipyretic use during pregnancy or infancy and an increased risk of asthma in 1490 mother-child pairs. The multivariate analysis, including type of drug, its dose and period of intake, and presence of infection, showed an increased risk of asthma, particularly in infancy, in those individuals who had been exposed to ibuprofen (OR 1.35; 95\% CI 1.19-1.52). However, adjusting for the presence of respiratory tract infection, this association appeared strongly attenuated (OR 1.19; 95\% CI 1.05-1.36) [55].

In another randomised controlled, double-blind trial in 100 schoolchildren with mild-to-moderate asthma, only $2 \%$ of the cases had ibuprofen-induced bronchospasm leading the authors to conclude that the prevalence of ibuprofen-associated asthma is low. Nevertheless, taking into account the prevalence of asthma among children, it is important to consider the possibility of ibuprofen-induced bronchospasm, especially in those children treated with ibuprofen during acute viral infections that can exacerbate asthma [56]. The hypothesis that short-term use of ibuprofen increases the risk of asthma attacks was investigated in a double-blind, randomised controlled trial by 


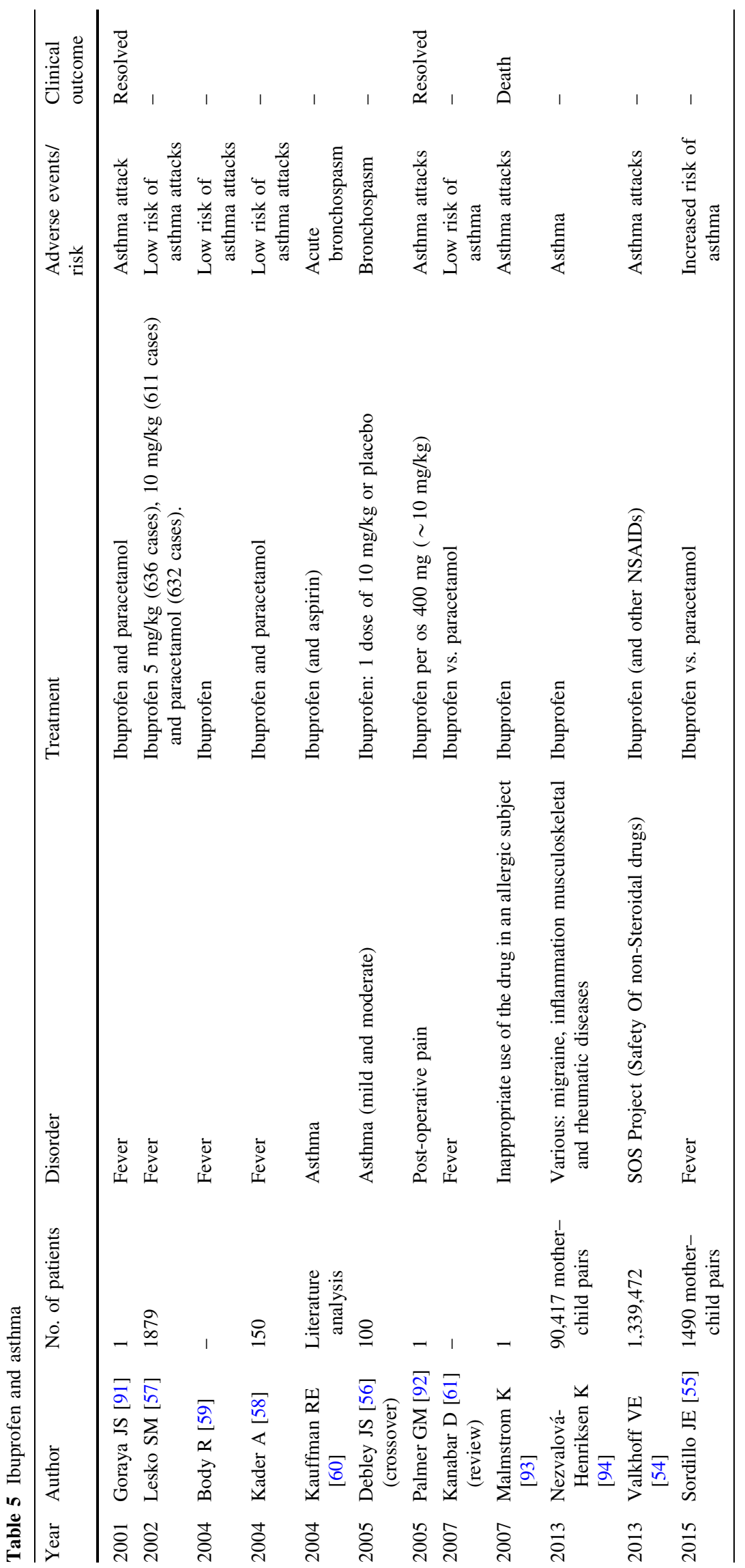


Lesko et al, who concluded that there was no proof that ibuprofen is less safe in asthmatics than in control children [57].

Two literature reviews conducted by Kader et al. [58] and Body et al. [59] showed that ibuprofen can be safely prescribed to febrile asthmatic children. Likewise, Kauffman et al. [60] found little evidence that the use of ibuprofen increases morbidity in asthmatic children and concluded that, although cross-reactions with aspirin and NSAID-induced asthma are possible, the use of ibuprofen is substantially safe in asthmatic children [60]. Another large review of the literature (472 articles) demonstrated that not only is there a low risk of ibuprofen-induced asthma in children, but that the drug might have protective and therapeutic effects [61]. Interestingly, it was recently suggested that ibuprofen reduces the late response to specific bronchoprovocation with allergens and could, therefore, have a protective effect in allergen-induced asthma [62], but further evidence is required.

Table 5 summarises the data on ibuprofen use and asthma in children.

\section{Tolerability Profiles in Other Conditions}

\subsection{Varicella}

Particular circumstances, such as viral infections and fever, seem to be associated with a higher rate of adverse events in people being treated with an NSAID.

Varicella is a viral infection that occurs especially in children who, inappropriately, have not been vaccinated. Recently, there has been an increase in complicated cases of varicella. The most frequent complications are bronchitis, pneumonia and superinfections of the skin. The pathogens involved in these secondary infections are GAS, which are also responsible for necrotising fasciitis (progressive necrosis of fascia). The risk of developing complications seems to be increased in people who have taken NSAIDs. This risk has been analysed in various clinical studies.

Lesko et al. [63] investigated the risk factors implicated in the development of necrotising fasciitis by studying 224 subjects with varicella (aged $<19$ years), of whom 52 with varicella complicated by a GAS infection and 172 with uncomplicated varicella, these latter patients forming the control group. Among the 224 children, 123 had taken ibuprofen or paracetamol (alone or in combination). The authors found that the use of ibuprofen was not associated with a higher risk of developing soft tissue necrosis, while the probability of a GAS infection was higher in subjects who had taken ibuprofen alone. The authors did, however, caution against uncritical interpretation of these statistical findings because of the risk of potential confounding factors. The subgroup that took both drugs also had a higher probability of a developing a GAS infection [63].

Byington et al. investigated the risk of empyema in subjects with pneumonia and a recent varicella infection by analysing the clinical records of 1093 children aged $<19$ years, of whom $540(49 \%)$ met the criteria for community-acquired pneumonia. In 153 of these patients, the pneumonia was complicated by empyema. The authors concluded that the risk of developing empyema was higher in children with varicella (OR 14.0; 95\% CI 2.3-86.5; $p<0.0001$ ) and in those treated with ibuprofen (OR 4.0; 95\% CI 2.5-6.5; $p<0.0001$ ) [64].

Mikaeloff et al. [65] followed-up subjects with varicella $(n=140,111)$ or zoster $(n=108,257)$ for 2 months after the diagnosis, in order to evaluate the development of skin or soft-tissue complications. There were 386 complications in the varicella group (mean age $10.7 \pm 14.5$ years): cellulitis $(n=271,70.2 \%)$, abscess $(n=107,27.7 \%)$,

Table 6 Ibuprofen and varicella

\begin{tabular}{|c|c|c|c|c|c|}
\hline Year & Author & $\begin{array}{l}\text { No. of } \\
\text { patients }\end{array}$ & Disorder & Treatment & Adverse events/risk \\
\hline 2001 & $\begin{array}{l}\text { Lesko SM } \\
\text { [63] }\end{array}$ & 224 & Varicella & $\begin{array}{l}\text { Ibuprofen alone or with } \\
\text { paracetamol }\end{array}$ & $\begin{array}{l}\text { GAS infections and necrosis of soft } \\
\text { tissues }\end{array}$ \\
\hline 2002 & $\begin{array}{l}\text { Byington } \\
\text { CL [64] }\end{array}$ & 540 & Varicella and pneumonia & Ibuprofen & Empyema \\
\hline 2008 & $\begin{array}{l}\text { Mikaeloff } \\
\text { Y [65] }\end{array}$ & 140,111 & Varicella & Ibuprofen (and other NSAIDs) & $\begin{array}{l}\text { Cellulitis, abscess, fasciitis and } \\
\text { necrosis }\end{array}$ \\
\hline 2008 & $\begin{array}{l}\text { Souyri C } \\
\text { [66] }\end{array}$ & 266 & $\begin{array}{l}\text { Varicella and other viral } \\
\text { infections }\end{array}$ & Ibuprofen (and other NSAIDs) & $\begin{array}{l}\text { Serious necrotising soft-tissue } \\
\text { infections }\end{array}$ \\
\hline 2015 & $\begin{array}{l}\text { Durand L } \\
\text { [67] }\end{array}$ & 3 & Varicella & NSAIDs, including ibuprofen & $\begin{array}{l}\text { Superinfection } \\
\text { Pleurisy-pneumonia }\end{array}$ \\
\hline
\end{tabular}

GAS group A streptococci, NSAIDs non-steroidal anti-inflammatory drugs 
fasciitis $(n=7,1.8 \%)$ and a single case of necrosis $(0.3 \%)$. Of these 386 subjects, $3.11 \%$ had been treated with NSAIDs (RR 4.9; 95\% CI 2.1-11.4), with ibuprofen being the most commonly used drug (85\%). On the basis of these data, the authors recommended caution when prescribing NSAIDs to people with varicella [65].

Souyri et al. [66] evaluated the contribution of NSAIDs to the development of severe necrotising soft tissue infections (NSTI) in 38 subjects with NSTI and 228 healthy subjects. The 38 subjects with NSTI were divided into three groups on the basis of age: 12 infants (0-23 months), 16 children ( $2-15$ years) and 10 adults ( $>15$ years). Among the group with NSTI, 25 patients had been prescribed ibuprofen (OR 31.38; 95\% CI 6.40-153.84) and 24 had varicella (OR 17.55; 95\% CI 3.47-88.65). This study indicates a strong association between the use of NSAIDs and severe NSTI, in particular in children with varicella [66]. In conclusion, it is worth being extremely cautious when prescribing ibuprofen to children with varicella because of the increased risk of complications [67].

Table 6 summarises the data on ibuprofen use in children with varicella.

\subsection{Stevens-Johnson Syndrome}

Stevens-Johnson syndrome (SJS) is considered a cellmediated delayed hypersensitivity reaction (type IV) to some drugs [68]. Clinically, SJS is manifested by variably severe cutaneous and mucosal lesions (ranging from papules and skin rashes to blisters and bullae), usually preceded by non-specific prodromal symptoms, such as fever, malaise, itchy eyes and dysphagia, which last for 1-14 days. In more severe cases, affected subjects may develop hypoalbuminaemia, electrolyte imbalances, increased azotaemia and glycaemia because of massive transdermal loss of fluid and a hypercatabolic state with sepsis and septic shock due to bacterial skin infections. With regards to pathophysiological mechanisms, the skin lesions seem to be due to widespread apoptosis of keratinocytes, although the way certain drugs induce necrosis of the epidermis is not yet understood. The blisters have been found to contain numerous CD8+ cytotoxic $\mathrm{T}$ cells and natural killer $\mathrm{T}$ cells which, through a variety of cytotoxic proteins and cytokines, such as soluble Fas ligand, perforin/granzyme and tumour necrosis factor- $\alpha$, could induce apoptosis of keratinocytes [68]. It has also been found that there is a genetic predisposition to the development of SJS: polymorphism of the CYP2C19 gene that codes for a particular cytochrome P450 isoform can increase the risk [68].

Numerous drugs have been implicated as possible causes of SJS. In a study of 32 children with SJS (aged

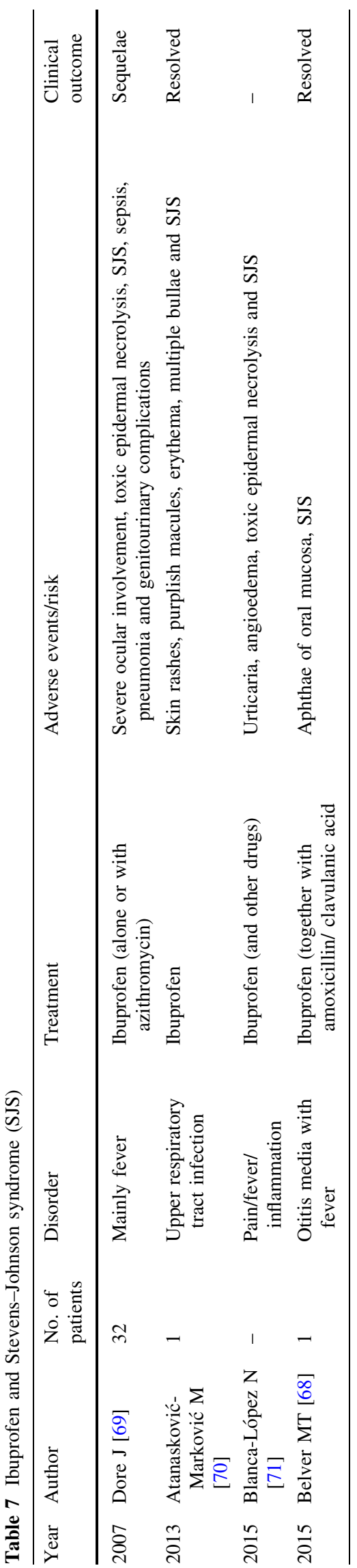


between 0 and 17 years), Dore et al. found an association between treatment with ibuprofen (alone or in combination with azithromycin) and the development of toxic epidermal necrolysis $(p<0.05)$ [69]. Atanasković-Marković et al. reported the case of a 9-year-old girl who, after 4 days of treatment with ibuprofen because of an upper respiratory tract infection, developed SJS with a skin rash, purplish macules, erythema and bullae. Six months later, the girl showed a positive reaction to a patch test with ibuprofen [70]. Belver et al. described the case of an 11-year-old boy with aphthae of the oral mucosa who was diagnosed with SJS following treatment with amoxicillin/clavulanic acid and ibuprofen. The SJS was confirmed by biopsy findings and in the acute symptomatic phase by a patch test and a lymphoblastic transformation test, which were both positive for ibuprofen [68]. Numerous hypersensitivity reactions to anti-inflammatory drugs are due to immunological mechanisms involving specific IgE antibodies or $\mathrm{T}$ cells. Blanca-López et al. concluded that ibuprofen is among the drugs that most frequently elicit IgE-mediated reactions, while T-cell-mediated reactions in children seem to be mainly associated with the intake of ibuprofen, naproxen and dipyrone [71].

Table 7 summarises the data on ibuprofen use and SJS in children.

Key points regarding pulmonary tolerability, use in patients with varicella and immunological consequences

Great care is needed when prescribing ibuprofen to children with severe infections of the upper or lower respiratory tract because of the risk of septic complications

Care is required when prescribing ibuprofen to children with asthma. In relation to the possibility of an exacerbation, patients should be advised to use salbutamol immediately

Ibuprofen should not be prescribed to patients with varicella, in order to avoid the risk of bacterial superinfections

The possibility of IgE-mediated or cell-mediated allergic reactions, including Steven-Johnson syndrome, should be considered

\subsection{Hepatic Tolerability}

Special attention should be paid to the risk, albeit low, of hepatic toxicity in children. Large paediatric studies have not revealed significant adverse hepatic effects [72]. However, Taghian et al. [73] and Kim et al. [74] described cases of vanishing bile duct syndrome as a possible complication of ibuprofen treatment for fever. Zaffanello et al. reported a case of combined acute renal and hepatic failure in a 5-year-old girl admitted to hospital for febrile seizures and vomiting who was given oral ibuprofen $(5 \mathrm{mg} / \mathrm{kg} / \mathrm{dose}$ 
every $8 \mathrm{~h}$, for a total of three doses) in alternation with paracetamol [75]. In all the above-described cases, the complications resolved without leaving clinical sequelae.

Table 8 summarises the data on the hepatic tolerability of ibuprofen in children.

\section{Conclusions}

The efficacy profile of ibuprofen has been extensively documented in the literature, with this NSAID being extremely effective in the treatment of pain, particularly in disorders with an inflammatory component, such as tonsillitis, pharyngitis and sore throat [17], acute otitis media [16], hip synovitis [19], and juvenile arthritis [20].

The daily dose is chosen on the bases of the age and weight of the child; the optimal analgesic dose of ibuprofen, administered orally, is $10 \mathrm{mg} / \mathrm{kg}$ every $8 \mathrm{~h}$. The cumulative daily dose should not exceed $30 \mathrm{mg} / \mathrm{kg}$.

This review summarises the main adverse reactions to ibuprofen given as monotherapy or in association with other drugs for the treatment of fever and pain, as reported in the paediatric literature in the last 15 years. It must be considered that findings may be associations not necessarily causal and not giving an overall idea of incidence in light of the population use of ibuprofen.

The most frequents adverse reactions involve the gastrointestinal, renal and respiratory systems.

The literature from 2000 to date demonstrates that gastrointestinal events are rare, but clinically relevant given that ibuprofen can cause intestinal in addition to gastric toxicity [7, 33].

Dehydration plays an important role in triggering renal damage by NSAIDs. Indeed, ibuprofen should not be given to children with profuse diarrhoea and vomiting, with or without fever. Some authors suggest that ibuprofen should not be given to children with fever, recommending the use of paracetamol because of its better tolerability profile $[42,76]$. The combination of two NSAIDs (especially if off-label) can increase the risk of adverse renal events.

In patients with respiratory tract infections, ibuprofen should be suggested only as treatment for pain [6].

Ibuprofen should never be administered to patients who are allergic to NSAIDs, because of the possible risk of hypersensitivity cross-reactions. It is contraindicated in infants and in children with bronchospasm and persistent asthma and/or during varicella. The use of ibuprofen should also be avoided during treatment of Kawasaki syndrome with acetylsalicylic acid, because of excessive anti-platelet activity.

In 52\% (29/55) of the analysed studies, ibuprofen was used for the treatment of febrile and flu-like symptoms. Considering that for some of the studies it is not possible to determine the reason for which the drug was administered, it is likely that treatment of fever accounted for more than $52 \%$. Therefore, the proportion of risk of adverse events due to use of the drug as an antipyretic could be even greater than apparent.

Currently, there is large consensus that ibuprofen should be used as an antipyretic only in those children not responding to paracetamol. The tenet that, with rare exceptions, fever per se is not harmful and should be treated only if above $37.5^{\circ} \mathrm{C}$ in association with general malaise, should always be kept in mind [77]. Still, ibuprofen is the safest NSAID for use in the paediatric population. Compared to ketoprofen, indicated for children over 6 years of age, ibuprofen has fewer side effects [6]. Nimesulide is contraindicated in patients aged under 12 years and ketorolac and acetylsalicylic acid in patients younger than 16.

In conclusion, in the light of evidence emerging from recent literature, ibuprofen is the drug of choice for the treatment of inflammatory pain. Caution should be exercised when using ibuprofen in those conditions, such as febrile states, predisposing to a risk NSAID-induced side effects.

\section{Compliance with Ethical Standards}

Funding source The preparation of this manuscript was supported by an unrestricted grant from Ethos S.r.l. Ethos S.r.l. had no role in the preparation of the manuscript or decisions about its submission for publication.

Financial disclosures The authors have no financial involvement with any organization or entity with a financial interest in or financial conflict with the subject matter or materials discussed in the manuscript.

Conflict of interest The authors (MdM, AC, AB, GDA \& GM) have no potential conflicts of interest to disclose.

Open Access This article is distributed under the terms of the Creative Commons Attribution-NonCommercial 4.0 International License (http://creativecommons.org/licenses/by-nc/4.0/), which permits any noncommercial use, distribution, and reproduction in any medium, provided you give appropriate credit to the original author(s) and the source, provide a link to the Creative Commons license, and indicate if changes were made.

\section{References}

1. Southey ER, Soares-Weiser K, Kleijnen J. Systematic review and meta-analysis of the clinical safety and tolerability of ibuprofen compared with paracetamol in paediatric pain and fever. Curr Med Res Opin. 2009;25:2207-22.

2. Pierce CA, Voss B. Efficacy and safety of ibuprofen and acetaminophen in children and adults: a meta-analysis and qualitative review. Ann Pharmacother. 2010;44:489-506.

3. Perrott DA, Piira T, Goodenough B, Champion GD. Efficacy and safety of acetaminophen vs ibuprofen for treating children's pain 
or fever: a meta-analysis. Arch Pediatr Adolesc Med. 2004;158:521-6.

4. Litalien C, Jacqz-Aigrain E. Risks and benefits of nonsteroidal anti-inflammatory drugs in children: a comparison with paracetamol. Paediatr Drugs. 2001;3:817-58.

5. Autret-Leca E. A general overview of the use of ibuprofen in paediatrics. Int J Clin Pract Suppl. 2003;135:9-12.

6. Baiardi P, Barbieri I, Del Principe D, Di Pietro P, Manzoni P, Marchetti F, Napoleone E, Rocchi F, Rossi P, Rossi R, Santuccio C, Zuccotti GV. Cautele sull'uso dei FANS nei bambini. Le raccomandazioni del Working Group Pediatrico dell'AIFA. Medico e Bambino. 2010;10:654-6.

7. Cardile S, Martinelli M, Barabino A, Gandullia P, Oliva S, Di Nardo G, et al. Italian survey on non-steroidal anti-inflammatory drugs and gastrointestinal bleeding in children. World J Gastroenterol. 2016;22:1877-83.

8. Balestracci A, Ezquer M, Elmo ME, Molini A, Thorel C, Torrents M, Toledo I. Ibuprofen-associated acute kidney injury in dehydrated children with acute gastroenteritis. Pediatr Nephrol. 2015;30:1873-8.

9. François P, Desrumaux A, Cans C, Pin I, Pavese P, Labarère J. Prevalence and risk factors of suppurative complications in children with pneumonia. Acta Paediatr. 2010;99:861-6.

10. Rainsford KD. Ibuprofen: pharmacology, efficacy and safety. Inflammopharmacology. 2009;17:275-342.

11. Martínez C, García-Martín E, Blanco G, Gamito FJ, Ladero JM, Agúndez JA. The effect of the cytochrome P450 CYP2C8 polymorphism on the disposition of (R)-ibuprofen enantiomer in healthy subjects. Br J Clin Pharmacol. 2005;59:62-9.

12. Hay AD, Costelloe C, Redmond NM, Montgomery AA, Fletcher M, Hollinghurst S, Peters TJ. Paracetamol plus ibuprofen for the treatment of fever in children (PITCH): randomised controlled trial. BMJ. 2008;337:a1302.

13. Clark E, Plint AC, Correll R, Gaboury I, Passi B. A randomized, controlled trial of acetaminophen, ibuprofen, and codeine for acute pain relief in children with musculoskeletal trauma. Pediatrics. 2007;119:460-7.

14. Hämäläinen ML, Hoppu K, Valkeila E, Santavuori P. Ibuprofen or acetaminophen for the acute treatment of migraine in children: a double-blind, randomized, placebo-controlled, crossover study. Neurology. 1997;48:103-7.

15. Moore PA, Acs G, Hargreaves JA. Postextraction pain relief in children: a clinical trial of liquid analgesics. Int J Clin Pharmacol Ther Toxicol. 1985;23:573-7.

16. Bertin L, Pons G, d'Athis P, Duhamel JF, Maudelonde C, Lasfargues $\mathrm{G}$, et al. A randomized, double-blind, multicentre controlled trial of ibuprofen versus acetaminophen and placebo for symptoms of acute otitis media in children. Fundam Clin Pharmacol. 1996;10:387-92.

17. Bertin L, Pons G, d'Athis P, Lasfargues G, Maudelonde C, Duhamel JF, Olive G. Randomized, double-blind, multicenter, controlled trial of ibuprofen versus acetaminophen (paracetamol) and placebo for treatment of symptoms of tonsillitis and pharyngitis in children. J Pediatr. 1991;119:811-4.

18. Wong T, Stang AS, Ganshorn H, Hartling L, Maconochie IK, Thomsen AM, Johnson DW. Cochrane in context: Combined and alternating paracetamol and ibuprofen therapy for febrile children. Evid Based Child Health. 2014;9:730-2.

19. Kermond S, Fink M, Graham K, Carlin JB, Barnett P. A randomized clinical trial: should the child with transient synovitis of the hip be treated with nonsteroidal anti-inflammatory drugs? Ann Emerg Med. 2002;40:294-9.

20. Steans A, Manners PJ, Robinson IG. A multicentre, long-term evaluation of the safety and efficacy of ibuprofen syrup in children with juvenile chronic arthritis. $\mathrm{Br} \mathrm{J}$ Clin Pract. 1990;44:172-5.
21. Poonai N, Bhullar G, Lin K, Papini A, Mainprize D, Howard J, et al. Oral administration of morphine versus ibuprofen to manage postfracture pain in children: a randomized trial. CMAJ. 2014;186:1358-63.

22. Wong I, St John-Green C, Walker SM. Opioid-sparing effects of perioperative paracetamol and nonsteroidal anti-inflammatory drugs (NSAIDs) in children. Paediatr Anaesth. 2013;23:475-95.

23. Konstan MW, Byard PJ, Hoppel CL, Davis PB. Effect of highdose ibuprofen in patients with cystic fibrosis. $\mathrm{N}$ Engl $\mathrm{J}$ Med. 1995;332:848-54.

24. Konstan MW. Treatment of airway inflammation in cystic fibrosis. Curr Opin Pulm Med. 1996;2:452-6.

25. Lahiri T, Guillet A, Diehl S, Ferguson M. High-dose ibuprofen is not associated with increased biomarkers of kidney injury in patients with cystic fibrosis. Pediatr Pulmonol. 2014;49:148-53.

26. Ohlsson A, Walia R, Shah SS. Ibuprofen for the treatment of patent ductus arteriosus in preterm or low birth weight (or both) infants. Cochrane Database Syst Rev. 2015;(2):CD003481. doi:10.1002/14651858.CD003481.

27. Rainsford KD. Structure-activity relationships of non-steroid anti-inflammatory drug 1 . gastric ulcerogenic activity. Inflamm Res. 1978;8:587-605.

28. Adebayo D, Bjarnason I. Is non-steroidal anti-inflammatory drug (NSAID) enteropathy clinically more important than NSAID gastropathy? Postgrad Med J. 2006;82:186-91.

29. Harirforoosh S, Asghar W, Jamali F. Adverse effects of nonsteroidal antiinflammatory drugs: an update of gastrointestinal, cardiovascular and renal complications. Pharm Pharm Sci. 2013;16(5):821-47.

30. Ng SC, Chan FK. NSAID-induced gastrointestinal and cardiovascular injury. Curr Opin Gastroenterol. 2010;26:611-7.

31. Laine L, Smith R, Min K, Chen C, Dubois RW. Systematic review: the lower gastrointestinal adverse effects of non-steroidal anti-inflammatory drugs. Aliment Pharmacol Ther. 2006;24:751-67.

32. Lanas A, Ferrandez A. NSAIDs and the colon. Curr Opin Gastroenterol. 2009;25:44-9.

33. Bianciotto M, Chiappini E, Raffaldi I, Gabiano C, Tovo PA, Sollai S, Italian Multicenter Study Group for Drug and Vaccine Safety in Children, et al. Drug use and upper gastrointestinal complications in children: a case-control study. Arch Dis Child. 2013;98:218-21.

34. Grimaldi-Bensouda L, Abenhaim L, Michaud L, Mouterde O, Jonville-Béra AP, Giraudeau B, et al. Clinical features and risk factors for upper gastrointestinal bleeding in children: a casecrossover study. Eur J Clin Pharmacol. 2010;66:831-7.

35. Lanas A, Gargallo CJ. Management of low-dose aspirin and clopidogrel in clinical practice: a gastrointestinal perspective. J Gastroenterol. 2015;50:626-37.

36. Usta M, Urganci N. Upper gastrointestinal bleeding in children: the role of Helicobacter pylori infection and non-steroidal antiinflammatory drug use. West Indian Med J. 2015;64:113-6.

37. Mo C, Sun G, Wang Y-Z, Lu M-L, Yang Y-S. PPI versus histamine $\mathrm{H} 2$ receptor antagonists for prevention of upper gastrointestinal injury associated with low- dose aspirin: systematic review and metaanalysis. PLoS One. 2015;10(7):e0131558.

38. Vandenplas Y, Rudolph CD, Di Lorenzo C, Hassall E, Liptak G, Mazur L, Sondheimer J, Staiano A, Thomson M, VeeremanWauters G, Wenzl TG, North American Society for Pediatric Gastroenterology Hepatology and Nutrition, European Society for Pediatric Gastroenterology Hepatology and Nutrition. Pediatric Gastroesophageal Reflux Clinical Practice Guidelines: Joint Recommendations of the North American Society of Pediatric Gastroenterology, Hepatology, and Nutrition and the European Society of Pediatric Gastroenterology, Hepatology, and Nutrition. J Pediatr Gastroenterol Nutr. 2009;49(4):498-547. 
39. Tighe M, Afzal NA, Bevan A, Hayen A, Munro A, Beattie RM. Pharmacological treatment of children with gastro-oesophageal reflux. Cochrane Database Syst Rev. 2014;(11):CD008550. doi:10.1002/14651858.CD008550.pub2.

40. Ulinski T, Guigonis V, Dunan O, Bensman A. Acute renal failure after treatment with non-steroidal anti-inflammatory drugs. Eur J Pediatr. 2004;163:148-50.

41. Wong W, Coward RJ, Morris MC. Ibuprofen induced acute renal failure in an infant. N Z Med J. 2001;114:431.

42. Leroy S, Mosca A, Landre-Peigne C, Cosson MA, Pons G. Ibuprofen in childhood: evidence-based review of efficacy and safety. Arch Pediatr. 2007;14:477-84.

43. Misurac JM, Knoderer CA, Leiser JD, Nailescu C, Wilson AC, Andreoli SP. Nonsteroidal anti-inflammatory drugs are an important cause of acute kidney injury in children. J Pediatr. 2013;162:1153-9.

44. Gallego N, Estepa R, Mampaso F, García-S F, Reche A, Ortuño J. Tubulointerstitial nephritis and asymptomatic uveitis. J Nephrol. 2000;13:373-6.

45. Dixit MP, Nguyen C, Carson T, Guedes B, Dixit NM, Bell JM, Wang Y. Non-steroidal anti-inflammatory drugs-associated acute interstitial nephritis with granular tubular basement membrane deposits. Pediatr Nephrol. 2008;23:145-8.

46. Krause I, Cleper R, Eisenstein B, Davidovits M. Acute renal failure, associated with non-steroidal anti-inflammatory drugs in healthy children. Pediatr Nephrol. 2005;20:1295-8.

47. Carmody JB, Charlton JR. Short term gestation, long term risk: prematurity and chronic kidney disease. Pediatrics. 2013;131:1168-79.

48. Le V, Kurnutala L, SchianodiCola J, Ahmed K, Yarmush J, Daniel Eloy J, Shapiro M, Haile M, Bekker A. Premedication with intravenous ibuprofen improves recovery characteristics and stress response in adults undergoing laparoscopic cholecystectomy: a randomized controlled trial. Pain Med. 2016 (pii: pnv113, Epub ahead of print).

49. Canan CH, Gokhale NS, Carruthers B, et al. Characterization of lung inflammation and its impact on macrophage function in aging. J Leukoc Biol. 2014;96:473-80.

50. Leroy S, Marc E, Bavoux F, Tréluyer JM, Gendrel D, Bréart G, et al. Hospitalization for severe bacterial infections in children after exposure to NSAIDs A prospective adverse drug reaction reporting study. Clin Drug Investig. 2010;30:179-85.

51. Elemraid MA, Thomas MF, Blain AP, North East of England Pediatric Respiratory Infection Study Group Newcastle upon Tyne, et al. Risk factors for the development of pleural empyema in children. UK. Pediatr Pulmonol. 2015;50:721-6.

52. Jaffe A, Balfour-Lynn IM. Treatment of severe small airways disease in children with cystic fibrosis: alternatives to corticosteroids. Paediatr Drugs. 2002;4:381-9.

53. Su YM, Huang CS, Wan KS. Short-term ibuprofen treatment and pulmonary function in children with asthma. Indian Pediatr. 2015;52:691-3.

54. Valkhoff VE, Schade R, 't Jong GW, Romio S, et al. Populationbased analysis of non-steroidal anti-inflammatory drug use among children in four European countries in the SOS project: what size of data platforms and which study designs do we need to assess safety issues? BMC Pediatr. 2013;13:192.

55. Sordillo JE, Scirica CV, Rifas-Shiman SL, et al. Prenatal and infant exposure to acetaminophen and ibuprofen and the risk for wheeze and asthma in children. J Allergy Clin Immunol. 2015;135:441-8.

56. Debley JS, Carter ER, Gibson RL, Rosenfeld M, Redding GJ. The prevalence of ibuprofen-sensitive asthma in children: a randomized controlled bronchoprovocation challenge study. J Pediatr. 2005;147:233-8.

57. Lesko SM, Louik C, Vezina RM, Mitchell AA. Asthma morbidity after the short-term use of ibuprofen in children. Pediatrics. 2002;109:E20.
58. Kader A, Hildebrandt T, Powell C. How safe is ibuprofen in febrile asthmatic children? Arch Dis Child. 2004;89:885-6.

59. Body R, Potier R. Best evidence topic report. Non-steroidal antiinflammatory drugs and exacerbations of asthma in children. Emerg Med J. 2004;21:713-4.

60. Kauffman RE, Lieh-Lai M. Ibuprofen and increased morbidity in children with asthma. Paediatr Drugs. 2004;6:267-72.

61. Kanabar D, Dale S, Rawat M. A review of ibuprofen and acetaminophen use in febrile children and the occurrence of asthmarelated symptoms. Clin Ther. 2007;29:2716-23.

62. Nomani S, Cockcroft DW, Davis BE. Allergen inhalation challenge, refractoriness and the effects of ibuprofen. Allergy Asthma Clin Immunol. 2016;12:24

63. Lesko SM, O’Brien KL, Schwartz B, Vezina R, Mitchell AA, et al. Invasive group A streptococcal infection and nonsteroidal antiinflammatory drug use among children with primary varicella. Pediatrics. 2001;107:1108-15.

64. Byington CL, Spencer LY, Johnson TA, Pavia AT, Allen D, Mason EO, et al. An epidemiological investigation of a sustained high rate of pediatric parapneumonic empyema: Risk factors and microbiological associations. Clin Infect Dis. 2002;34:434-40.

65. Mikaeloff Y, Kezouh A, Suissa S. Nonsteroidal anti-inflammatory drug use and the risk of severe skin and soft tissue complications in patients with varicella or zoster disease. Br J Clin Pharmacol. 2008;65:203-9.

66. Souyri C, Olivier P, Grolleau S, Lapeyre-Mestre M, French Network of Pharmacovigilance Centres. Severe necrotizing softtissue infections and nonsteroidal anti-inflammatory drugs. Clin Exp Dermatol. 2008;33:249-55.

67. Durand L, Sachs P, Lemaitre C, Lorrot M, Bassehila J, Bourdon O, Prot-Labarthe S. NSAIDs in paediatrics: caution with varicella! Int J Clin Pharm. 2015;37:975-7.

68. Belver MT, Michavila A, Bobolea I, Feito M, Bellon T, Quice S. Severe delayed skin reactions related to drugs in the paediatric age group: a review of the subject by way of three cases (Stevens-Johnson syndrome, toxic epidermal necrolysis and DRESS). Allergologia et Immunopathologia. 2016;44:83-95.

69. Dore J, Salisbury RE. Morbidity and mortality of mucocutaneous diseases in the pediatric population at a tertiary care center. J Burn Care Res. 2007;28:865-70.

70. Atanasković-Marković M, Medjo B, Gavrović-Jankulović M, Ćirković Veličković T, Nikolić D, Nestorović B. Stevens-Johnson syndrome and toxic epidermal necrolysis in children. Pediatr Allergy Immunol. 2013;24:645-9.

71. Blanca-López N, Cornejo-García JA, Pérez-Alzate D, et al. Hypersensitivity reactions to nonsteroidal anti-inflammatory drugs in children and adolescents: selective reactions. J Investig Allergol Clin Immunol. 2015;25:385-95.

72. Argentieri J, Morrone K, Pollack Y. Acetaminophen and ibuprofen overdosage. Pediatr Rev. 2012;33:188-9.

73. Taghian M, Tran TA, Bresson-Hadni S, Menget A, Felix S, Jacquemin E. Acute vanishing bile duct syndrome after ibuprofen therapy in a child. J Pediatr. 2004;145:273-6.

74. Kim HY, Yang HK, Kim SH, Park JH. Ibuprofen associated acute vanishing bile duct syndrome and toxic epidermal necrolysis in an infant. Yonsei Med J. 2014;55:834-7.

75. Zaffanello M, Brugnara M, Angeli S, Cuzzolin L. Acute nonoliguric kidney failure and cholestatic hepatitis induced by ibuprofen and acetaminophen: a case report. Acta Pædiatr. 2009;98:901-9.

76. Berezin HS, Bostwick HE, Halata MS, Feerick J, Newman LJ, Medow MS. Gastrointestinal bleeding in children following ingestion of low-dose ibuprofen. J Pediatr Gastroenterol Nutr. 2007:44:506-8. 
77. de Martino M, Chiarugi A. Recent advances in pediatric use of oral paracetamol in fever and pain management. Pain Ther. 2015;4:149-68.

78. Raju NV, Bharadwaj RA, Thomas R, Konduri GG. Ibuprofen use to reduce the incidence and severity of bronchopulmonary dysplasia: a pilot study. J Perinatol. 2000;20(1):13-6.

79. Aho M, Kokki H, Nikanne E. Nimesulide versus ibuprofen for postoperative tonsillectomy pain: a double-blind, randomised, active comparator-controlled clinical trial. Clin Drug Investig. 2003;23(10):651-60.

80. Clarke SF, Arepalli N, Armstrong C, Dargan PI. Duodenal perforation after ibuprofen overdose. J Toxicol Clin Toxicol. 2004;42(7):983-5.

81. Mackey JE, Anbar RD. High-dose ibuprofen therapy associated with esophageal ulceration after pneumonectomy in a patient with cystic fibrosis: a case report. BMC Pediatr. 2004;4:19.

82. Titchen $\mathrm{T}$, Cranswick N, Beggs S. Adverse drug reactions to nonsteroidal anti-inflammatory drugs, COX-2 inhibitors and paracetamol in a paediatric hospital. $\mathrm{Br} \mathrm{J}$ Clin Pharmacol. 2005;59(6):718-23.

83. Gobbi D, Billi P. Fascetti Leon F, Alvisi P, Lambertini A, Lima M. Pneumatic pyloric dilatation forthe treatment of gastric outlet obstruction in a child. Pediatr Int. 2013;55(3):382-5.

84. Vaquero Sosa E, Bodas Pinedo A, Maluenda Carrillo C. Gastrointestinal bleeding followingingestion of low-dose ibuprofen. An Pediatr. 2013;78(1):51-3. doi:10.1016/j.anpedi.2012.05.012.

85. Del Vecchio MT, Sundel ER. Alternating antipyretics: is this an alternative? Pediatrics. 2001;108(5):1236-7.
86. Moghal NE, Hegde S, Eastham KM. Ibuprofen and acute renal failure in a toddler. Arch Dis Child. 2004;89(3):276-7.

87. Yue Z, Jiang P, Sun H, Wu J. Association between an excess risk of acute kidney injury and concomitant use of ibuprofen and acetaminophen in children, retrospective analysis of a spontaneousreporting system. Eur J Clin Pharmacol. 2014;70(4):479-82.

88. Oker EE, Hermann L, Baum CR, Fentzke KM, Sigg T, Leikin JB. Serious toxicity in a young child due to ibuprofen. Acad Emerg Med. 2000;7(7):821-3.

89. Baird JS, Greene A, Schleien CL. Massive pulmonary embolus without hypoxemia. Pediatr Crit Care Med. 2005;6(5):602-3.

90. Iancovici Kidon M, Abramovitch I, Steinberg S, Barash J. Crossreactive hypersensitivity to $\mathrm{COX}$ inhibitors in a child with mild allergic rhinitis. Isr Med Assoc J. 2005;7(12):790-1.

91. Goraya JS, Virdi VS. To the editor: exacerbation of asthma by ibuprofen in a very young child. Pediatr Pulmonol. 2001;32(3):262.

92. Palmer GM. A teenager with severe asthma exacerbation following ibuprofen. Anaesth Intensive Care. 2005;33(2):261-5.

93. Malmström K, Kaila M, Kajosaari M, Syvänen P, JuntunenBackman K. Fatal asthma in Finnish children and adolescents 1976-1998: validity of death certificates and a clinical description. Pediatr Pulmonol. 2007;42(3):210-5.

94. Nezvalová-Henriksen K, Spigset O, Nordeng H. Effects of ibuprofen, diclofenac, naproxen, and piroxicam on the course of pregnancy and pregnancy outcome: a prospective cohort study. BJOG. 2013;120(8):948-59. 